\title{
Comorbidity of Cerebral Palsy, the Cyst of the Corpus Callosum, Parenchymal Cyst, Epilepsy and Cardiac Disease: About an Observation
}

\author{
Patrice Ntenga ${ }^{1,2 *}$, K. Kabulo ${ }^{3}$, Patrick Mutombo ${ }^{2}$, A. Mulumba ${ }^{2}$, E. Lowakondjo², \\ Dirk Teuwen $^{2}$, Marième Soda Diop-Sène ${ }^{1}$, A. A. Nahantchi ${ }^{1}$, N. S. Diagne ${ }^{1}$, K. Tourée,4, \\ M. Ndiaye ${ }^{1}$, A. Gallo Diop ${ }^{1}$ \\ ${ }^{1}$ Neurological Clinic of the National Teaching Hospital, FANN, Dakar, Senegal \\ ${ }^{2}$ Neuropsychiatric Center Joseph Guislain of the Brothers of Charity, Lubumbashi, Congo \\ ${ }^{3}$ Department of Neurosurgery, University of Zimbabwe, Harare, Zimbabwe \\ ${ }^{4}$ Department of Preventive Medicine and Public Health, Faculty of Medicine, Pharmacy and Odontostomatology, \\ University of Cheikh Anta Diop, Dakar, Senegal \\ Email: ${ }^{\star}$ jacobntenga@gmail.com
}

How to cite this paper: Ntenga, P., Kabulo, K., Mutombo, P., Mulumba, A., Lowakondjo, E., Teuwen, D., Diop-Sène, M.S., Nahantchi, A.A., Diagne, N.S., Touré, K., Ndiaye, M. and Diop, A.G. (2018) Comorbidity of Cerebral Palsy, the Cyst of the Corpus Callosum, Parenchymal Cyst, Epilepsy and Cardiac Disease: About an Observation. Yangtze Medicine, 2, 39-45. https://doi.org/10.4236/ym.2018.21004

Received: November 8, 2017

Accepted: March 24, 2018

Published: March 27, 2018

Copyright (c) 2018 by authors and Scientific Research Publishing Inc. This work is licensed under the Creative Commons Attribution International License (CC BY 4.0).

http://creativecommons.org/licenses/by/4.0/

\section{c) (i) Open Access}

\begin{abstract}
Motor impairment of cerebral origin is a syndrome that induces a reduction in activity, the origin of which is brain injury or a non-progressive and definitive abnormality occurring in a developing immature brain. Motor disability, spastic, dyskinetic or ataxic, is often associated with sensory, cognitive, sensory and behavioral disorders with or without epileptic disease. View of accidental discoveries of corpus callosum abnormalities, most often asymptomatic or associated with psychomotor retardation, epilepsy, neurological disorders or cardiomyopathy, a high technical platform must be available for its diagnosis. We report in this article the case of a 7-year-old boy followed at the neuropsychiatric center Joseph Guislain of the Brothers of Charity of Lubumbashi in Congo (DRC) since 2016 for generalized tonic-clonic seizures, in whom the diagnosis of cerebral palsy on cyst of corpus callosum and in the right parietal lobe, as well as cardiopathy was posed during its consultation in September 2017. This case was published with parental consent.
\end{abstract}

\section{Keywords}

Cerebral Palsy, Cyst of the Corpus Callosum, Parenchymal Cyst, Epilepsy, Heart Disease

\section{Introduction}

Cerebral palsy is not a disease, but a syndrome that associates permanent 
movement and posture disorders, thus inducing a reduction in activity, the origin of which is a cerebral lesion or non-progressive and definitive abnormality in a developing immature brain. Motor disability, spastic, dyskinetic or ataxic is often associated with sensitive, cognitive, sensorial and behavioral disorders with or without epileptic disease. Spastic motor disorders are classified as unilateral (hemiplegia) and bilateral (diplegia or quadriplegia) [1].

This syndrome is a second component of the child's disability, $19 \%$ of children with disabilities. The degree of disability is very variable, ranging from a discreet spasticity just barely impeding the walking to large retractions making the motor skills almost impossible.

The etiology of cerebral palsy is almost always related to birth conditions: obstetrical trauma (56\%), prematurity (30\%), various neonatal pathology (nuclear jaundice). This etiology emphasizes the importance of prevention in order to significantly reduce the frequency [1].

Since 1980, cerebral motricity is the French language magazine providing extensive information on cerebral palsy. Multiple articles ranging from screening and clinical assessment to therapeutic education, prevention and orthopedic treatment, swallowing and feeding disorders and neuropsychological aspects [2]. Professionals with real experience in our community underestimate its prevalence. We report in this article the case of a young boy followed at the neuropsychiatric center Joseph Guislain of the Brothers of Charity since 2016 for generalized tonic-clonic seizures, in whom the diagnosis of a cerebral palsy, polyhandicap on cyst of the corpus callosum and of the right parietal lobe, was retained during its consultation in September 2017.

\section{Observation}

This was the 7-year-old child, male, living in Lubumbashi, who was brought by his parents for generalized tonic-clonic convulsive seizures, sometimes left-sided tonic seizures. These crises had changed since the age of 2 years. It has been noted in his antecedents a eutocic term delivery with a weight of $2600 \mathrm{~kg}$. The boy was transfused at 2 weeks after birth, and had suffered from meningitis at the age of one month after birth. The examination showed a weight of $19 \mathrm{~kg}$, axial hypotonia, hypertonia of the limbs predominant to the lower limbs, retarded psychomotor development (cannot sit or walk) so a child we call BTBED (back-thigh-bed), no language, follow the movement of objects (Figure 1). There was a bilateral pyramidal syndrome, a mitral systolic murmur at intensity $4 / 6$, the electrocardiogram was not performed. The feet were in equine varus. Sudden noises and skin contact, as well as rapid movements of mobile elements in the attentional field of vision, caused in our patient a sudden disorganization of gestural motricity, both as an imbalance and a disorder in manual activities. In front of this picture a cerebral palsy was evoked. Thus, a cerebral CT scan showed ventricular dilatation and cortico-subcortical atrophy, a cyst of the corpus callosum, a cyst in the right parietal lobe (Figure 2). An electroencephalogram 


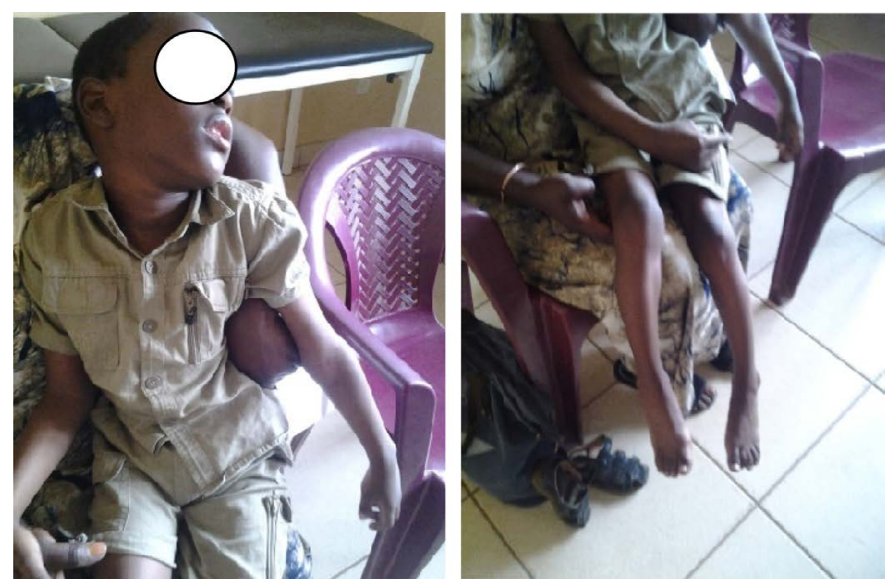

Figure 1.7 years old, equine varus.

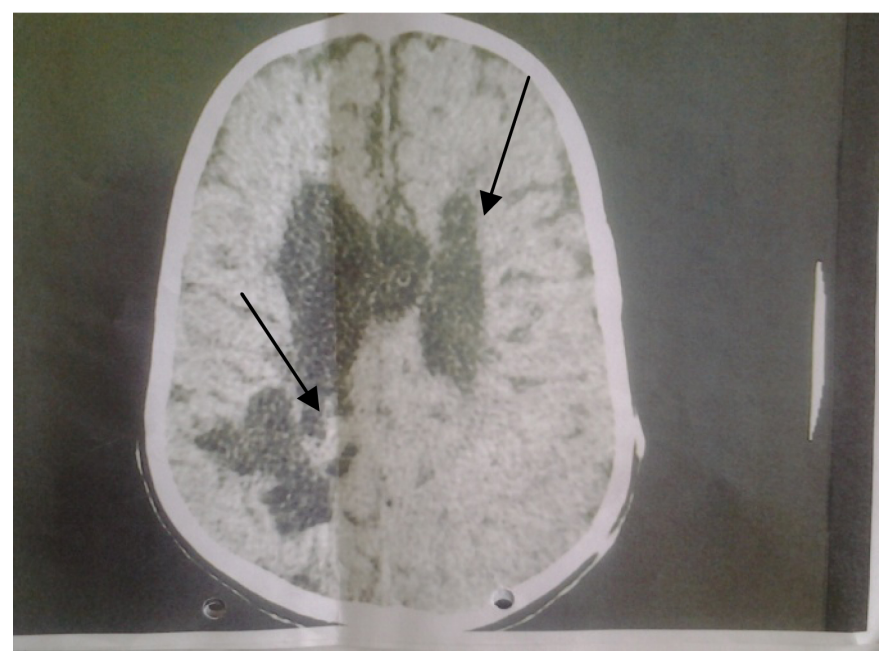

Figure 2. CT scan axial section showing Cyst of the corpus callosum and in the right parieto-occipital lobe, cortico-cortical atrophy.

performed, showed a very slow track as a whole. A neurosurgical indication had found its place. Due to a lack of neurosurgeon in the environment and poor socio-economic conditions, the child benefited from a drug treatment based on sodium valproate at a dose of $20 \mathrm{mg} / \mathrm{kg}$, pending the solution.

\section{Discussion}

The overall prevalence of cerebral palsy in developed countries is in the range of 1.6 to 3.0/1000 [1] [3] [4]. It is also known that this rate would increase from 40 to $100 / 1000$ in case of severe prematurity or extreme prematurity. In our community, this prevalence is not known due to lack of related studies. Some other authors estimated that prematurity aggravated by multiple pregnancies or medically assisted procreation accounted for $35 \%-55 \%$ of cases of cerebral palsy [5] [6] [7]. It would still be important to correlate this data with local data.

Some authors still think that at the origin of these cerebral motor disabilities, full term infants would represent $38 \%$ of cases with a prenatal factor and in $35 \%$ 
of cases with a perinatal or neonatal circumstance, whereas in premature infants the figures would be reversed, with $49 \%$ of cases directly related to the circumstances of delivery or neonatal care, compared to $17 \%$ of antenatal factors [7].

In a large series, nuclear magnetic resonance imaging (MRI) is designed to precisely locate brain lesions [8]. In case of cerebral palsy, some authors have shown that the routine practice of MRI has shown that $80 \%$ of children with asphyxia encephalopathy have deep gray matter, cortex and white matter lesions in case of cerebral palsy [9]. Our patient did not receive an MRI due to the non-availability of this examination in a medium low technical setting, and this could impact the diagnosis, prevalence and management. At least cerebral CT showed ventricular dilatation and cortico-subcortical atrophy, a cyst of the corpus callosum and in the right parietal lobe, which corroborates the lesions of the cerebral parenchyma and the white matter (corpus callosum) as described above.

Unlike other cerebral palsy subjects who are subject to external stress and who have no more reactions than valid subjects, as reported by M. Le Métayer [10], our patient has shown a correlation between excessive reactions to all three types of external solicitations: sudden sound, cutaneous contacts and displacement in the visual field.

Badawi N. et al. [11], showed in their study that the severe encephalopathies evolved unfavorably in $62 \%$ of the cases with a third of neonatal deaths and a third of neurological abnormalities and that moderate encephalopathies lead to an abnormal progression in $25 \%$ of cases, of which $10 \%$ was motor impairment, and that seizures were a derogatory sign because they increased the risk of cerebral palsy by 3. In this same study, it has been reported that in the absence of motor infirmity, disabilities predominate over language and comprehension. Relative to other cerebral palsy, regardless of their origin, handicaps secondary to severe ischemic antenatal encephalopathy most often affected boys and were quadriplegic or dyskinetic, and more frequently associated with epilepsy. C Bordonne et al., Have been able to identify several risk factors for drug resistance, including the existence of associated clinical and imaging abnormalities, defining symptomatic epilepsy [12], and this justifies the persistence of epileptic seizures at our patient.

It is known that in order to organize and plan our actions, we need proprioceptive, tactile and visual information, as well as the mental aptitudes necessary to treat them and memorize errors as motor successes. Having a progressively enriched praxis baggage, we can adapt to situations that are more and more varied in our encounters with the outside world, but the cerebromotor components remain indispensable in the transition to action, and therefore in learning [13]. On the other hand, the very altered psychomotor state of our patient does not allow him to learn, this raises concerns in the reeducation of children with a severe deficiency of speech which does not only cause an incapacity in oral communication but intervenes also in the neuro-psychological dysfunctions involved in learning disabilities of reading. This severe or profound motor impairment leads to an extreme limitation of autonomy and possibilities of percep- 
tion, expression and relationship. But, for their part, F. Marchal et al. [14] have shown that learning to read in children has been the subject of much work in the last ten years (a mini literature review). Those who dealt with the relations between spoken and written language are currently enriching the neuropsychological approach in non-oralizing children with cerebral palsy. The rehabilitation and pedagogical approach then proposed should discuss the contribution of a telethesis, "prosthesis" of speech. We believe that this approach is still widely applicable in the socio-economically weaker regions and in addition suffering from the lack of qualified personnel. However, where feasibility is possible, we believe that in terms of relationships, sensory and education, a special approach to multi-handicapped subjects is most often necessary as in our patient (Lesson for readers).

In the factorial analysis of these children one element is constant: the frequency of the polyhandicap (42\%) of the severely handicapped children suffers from a polyhandicap: severe mental deficiency, cerebral palsy, comitiality, behavioral disorders [14].

Our 7 year old patient corroborates from the point of view age and sex most of literatures [14]. On the other hand, S. Bourelle et al. [15] noted four children with spastic diplegia including one boy and three girls all aged between 5 and 14 years old, and they had a fixed or dynamic equine or two-sided that required management, medical injection of botulinum toxin and/or plaster lengthening, or surgical aponeurotomy of the twins. This child had been suffering for many days because of the diagnostic and therapeutic orientation in his environment. For some other authors [16], only a few observations have been published, all of which showed the benefit of the local injection toxin in painful dystonia of the para-spinal muscles, both in a neurological context and in the context of chronic low back pain [17]. Hence the interest of a long series of studies on the use of botulinum toxin in subjects with cerebral palsy.

In the series of E. Awazu [18], the rate of associated corpus callosum abnormalities was found to be $70 \%$ with $61 \%$ of polymalform fetuses. The same study included $46 \%$ brain abnormalities and $65 \%$ other abnormalities ( $41 \%$ of facial dysmorphisms, $33 \%$ of extremity abnormalities and $28 \%$ of congenital heart defects).

\section{Conclusion}

The diagnosis of cerebral palsy associated with abnormalities of the corpus callosum as a whole and epilepsy and cardiomyopathy is still a diagnostic problem in settings with limited resources and this underestimates its prevalence and incidence. Given its impact on the future of the child, the education of the medical profession on antenatal, peri and neonatal surveillance is essential in these environments (Lesson for readers).

\section{References}

[1] Krägeloh-Mann, I. and Cans, C. (2009) Cerebral Palsy Update. Brain \& Development, 
31, 537-544. https://doi.org/10.1016/j.braindev.2009.03.009

[2] Le Métayer, M. (2007) Cerebral Palsy and Polyhandicap. Brain Motricity, 28, 147-148.

[3] Westbom, L., Hagglund, G. and Nordmark, E. (2007) Cerebral Palsy in a Total Population of 4-11-Year Olds in Southern Sweden, Prevalence and Distribution According to Different CP Classification Systems. BMC Pediatrics, 7, 4. https://doi.org/10.1186/1471-2431-7-41

[4] Andersen, G.L., Irgens, L.M., Haagaas, I., Skranes, J.S., Moberg, A.E. and Vik, T. (2008) Cerebral Palsy in Norway: Prevalence, Subtypes and Severity. European Journal of Paediatric Neurology, 12, 4-13. https://doi.org/10.1016/j.ejpn.2007.05.001

[5] Amiel-Tison, V.C. (2005) Sequential Aspects of Perinatal Brain Lesions: Motor Impairment of Cerebral Origin. In: Perinatal Neurology, 3th Edition, Masson, Paris, 227-237.

[6] Thorngren-Jerneck, K. and Herbst, A. (2006) Perinatal Factors Associated with Cerebral Palsy in Children Born in Sweden. Obstetrics \& Gynecology, 108, 1499-1505. https://doi.org/10.1097/01.AOG.0000247174.27979.6b

[7] Hagberg, B., Hagberg, G., Beckung, E. and Uvebrant, P. (2001) Changing Panorama of Cerebral Palsy in Sweden. VIII. Prevalence and Origin in the Birth Year Period 1991-1994. Acta Paediatrica, 90, 271-277.

https://doi.org/10.1080/080352501300067532

[8] Barkovich, A.J., Hajnal, B.L., Vigneron, D., Sola, A., Partridge, J.C., Allen, F., et al. (1998) Prediction of Neuromotor Outcome in Perinatal Asphyxia: Evaluation of MR Scoring Systems. American Journal of Neuroradiology, 19, 143-149.

[9] Cowan, F., Rutherford, M., Groenendaal, F., Eken, P., Mercuri, E., Bydder, G.M., et al. (2003) Origin and Timing of Brain Lesions in Term Infants with Neonatal Encephalopathy. Lancet, 361, 736-742. https://doi.org/10.1016/S0140-6736(03)12658-X

[10] Le Métayer, M. (2010) What about Clinical Examination in Cerebral Palsy? What Re-Educational Perspectives? Brain Motricity, 31, 152-163.

[11] Badawi, N., Felix, J.F., Kurinczuk, J.J., Dixon, G., Watson, L., Keogh, J.M., et al. (2005) Cerebral, Palsy Following Term Newborn Encephalopathy: A Population Based Study. Developmental Medicine \& Child Neurology, 47, 293-298. https://doi.org/10.1017/S0012162205000575

[12] Bordonne, C., Delalandeet, O. and Heran, F. (2010) Disability and Epilepsy. Journal de Radiologie, 91, 1398-1405. https://doi.org/10.1016/S0221-0363(10)70219-5

[13] Le Métayer, M. (2009) The Cerebro Motor Assessment of the Young Child. Encyclopedia Surgical Medicine, Physiotherapy-Medicine Rehabilitation.

[14] Marchal, F., Aupiais, B., Dhellemmes, J., Varillon, S., Kessler, C., Morel, R. and Quentin, V. (2002) Telethesis and Learning to Read in a Child BMI without Speech. Ann readjustment Méd Phys, 45, 325-327.

[15] Bourelle, S., Cottalorda, J., Bessenay, L. and Gautheron, V. (2002) In Their Study on the Postural Evaluation of Children Cerebral Motor Diseases after Treatment of an Equine. Ann readjustmentMédPhys, 45, 325-327.

[16] Gallien, P., Nicolas, B., Petrilli, S., Kerdoncuff, V., Lassalles, A. and Durufle, A. (2002) Interest of Botulinum Toxin in the Rachialgies of Adult BMI. About an Observation. Ann readjustment MédPhys, 45, 325-327.

[17] Comella, C.L., Schannon, K.M. and Jaglin, J. (1998) Extensortruncal Dystonia: Successful Treatment with Botulinum Toxin Injections. Movement Disorders, 13, 
552-555. https://doi.org/10.1002/mds.870130330

[18] Awazu, E. (n.d.) Antenatal Diagnosis of Dysgenesis of the Corpus Callosum and Become Neurological, Experience of Nantes 2002-2010. 